\title{
IMPACTOS DA APLICAÇÃO DE LODO DE ESGOTO NA CULTURA DA CANA-DE-AÇÚCAR E NO AMBIENTE
}

\author{
IMPACTS OF SEWAGE SLUDGE APPLICATION ON \\ SUGARCANE CROP AND ON ENVIRONMENT
}

\section{Fábio César da Silva ${ }^{1}$, Antonio Enedi Boaretto ${ }^{2}$; Cássio Hamilton Abreu Junior ${ }^{2}$, Ronaldo Severiano Berton ${ }^{3}$, Luiz Carlos Basso $^{4}$, Valter Barbieri ${ }^{5}$}

${ }^{1}$ Pesquisador da Embrapa Informática Agropecuária e Professor da FATEC Piracicaba / FATEP- IAT, Av. André Tosello, 209 - Barão Geraldo Caixa Postal 6041- 13083-886 - Campinas, SP, e-mail: fcesar@cnptia.embrapa.br

${ }^{2}$ Pesquisador da Seção de Nutrição de Plantas CENA/USP, Piracicaba-SP. Bolsista CNPq. e-mail: aeboaret@cena.usp.br

${ }^{2}$ Universidade de São Paulo, Laboratório de Nutrição Mineral de Plantas.

Av. Centenário, 303 São Dimas - CEP:13400-970 - Piracicaba, SP - e-mail: cahabreu@cena.usp.br

${ }^{3}$ Instituto Agronômico de Campinas, Centro de Solos e Recursos Agroambientais.

Av. Barão de Itapura 1481 Guanabara 13020-902 - Campinas, SP - e-mail: berton@iac.sp.gov.br

${ }^{4}$ Professor Doutor do Departamentos de Ciências Biológicas- Esalq/USP, Piracicaba SP.e-mail: lucbasso@esalq.usp.br

${ }^{5}$ Professor Doutor do Departamentos de Ciências Exatas- Esalq/USP, Piracicaba SP. e-mail: vbarbier@esalq.usp.br

\section{RESUMO}

A pesquisa de campo teve por objetivo avaliar os efeitos da aplicação de lodo de esgoto (LE), complementado ou não com adubos NP, NK, PK e NPK, sobre a nutrição e produtividade da cultura de cana-de-açúcar, para caracterizar o potencial do lodo em fornecer nutrientes, e os possíveis impactos ambientais devido à presença de metais pesados em um Argissolo Vermelho-Amarelo distrófico. O LE foi aplicado nas doses de 0, 20 e $40 \mathrm{t} \mathrm{ha}^{-1}$ (material úmido, com $620 \mathrm{~g} \mathrm{~kg}^{-1}$ de água) e o N, P e K, respectivamente, nas doses de 34,60 e $83 \mathrm{~kg} \mathrm{ha}^{-1}$. Em amostras de folhas +1 da canade-açúcar, coletadas aos 146 dias após o plantio (dap), e de parte aérea total (colmo + folha), coletadas na época da colheita, foram analisados os teores de nutrientes e metais traços. O LE se mostrou adequado como fertilizante para a cana-de-açúcar, em 
cultivo de 18 meses, fornecendo principalmente $\mathrm{Ca}, \mathrm{P}, \mathrm{S}$ e $\mathrm{Zn}$, aumentando a atividade da fosfatase ácida e a produtividade de biomassa e de açúcar em função linear das doses de LE. Dentre os nutrientes fornecidos pelo LE, constatou-se que o $\mathrm{P}$ não foi o único responsável pelo aumento da produtividade de colmos, devido aumento da taxa fotossintética, pois houve alteração no balanço secundário das fosfatases ácidas por $\mathrm{Cu}, \mathrm{Zn}$ e $\mathrm{B}$, como prováveis catalisadores enzimáticos. Houve aumentos nas exportações de $\mathrm{N}, \mathrm{Ca}, \mathrm{P}, \mathrm{Mg}, \mathrm{S}, \mathrm{Se}, \mathrm{Fe}, \mathrm{Al}, \mathrm{Cu}, \mathrm{B}, \mathrm{Cd}$ e $\mathrm{Zn}$ pela parte aérea com a adição de $\mathrm{LE}$, causados pelos acréscimos dos teores de $\mathrm{B}, \mathrm{Ca}, \mathrm{Cu}, \mathrm{S}$ e $\mathrm{Zn}$ no tecido vegetal e/ou, pela maior produtividade de biomassa. Comparando-se as quantidades de nutrientes exportadas pela parte aérea com aquelas adicionadas ao solo pela aplicação de $40 \mathrm{tha}^{-1}$ de LE, constatou-se que as entradas foram positivas, exceto para o B e K, cujo balanço foi negativo.

Palavras-chave: Sacharum spp. Metais-traços. Fosfatase ácida. Disposição agrícola de resíduo. Impacto ambiental.

\section{ABSTRACT}

This field research aimed to evaluate the effects of sewage sludge (SS) application, complemented or not with NP, NK, and NPK fertilizers, on sugarcane crop nutrition and yield to characterize the SS nutrient supplying potential, and the possible environment impacts due to SS-contained heavy metals in an Arenic Abruptic Paleudult. The SS was applied at doses of 0, 20 and $40 \mathrm{t} \mathrm{ha}^{-1}$ (wet material, with $620 \mathrm{~g} \mathrm{~kg}^{-1}$ of water), and $\mathrm{N}, \mathrm{P}$ and $\mathrm{K}$, respectively, at doses of 34,60 and $83 \mathrm{~kg}$ $\mathrm{ha}^{-1}$. The nutrients and heavy metals' concentration were determined in samples of sugarcane +1 leaves and above ground (stalks plus leaves). Leaves were sampled at 146 days after planting (dap), and the above ground part, at cane harvesting. The SS was a fertilizer-like to sugarcane crop cultivated during 18 months, mostly for supplying adequate levels of $\mathrm{Ca}, \mathrm{P}, \mathrm{S}$ and $\mathrm{Zn}$. As effects of this, there were increases on acid phosphatase activity, and on biomass and sugar yields, in linear function of SS doses. Within the nutrients supplied by SS, it was verified that P was not the unique responsible for increasing stark yield, due to higher photosynthetic rate, once the phosphatases' secondary balance was altered by $\mathrm{Cu}, \mathrm{Zn}$ and $\mathrm{B}$ metals, probably as enzymatic catalyst. There were increases in $\mathrm{N}, \mathrm{Ca}, \mathrm{P}, \mathrm{Mg}, \mathrm{S}, \mathrm{Fe}, \mathrm{Cu}, \mathrm{B}$ and $\mathrm{Zn}$ exportations by above ground part with SS addition, which were consequence of higher contents of $\mathrm{B}, \mathrm{Ca}, \mathrm{Cu}, \mathrm{S}$ and $\mathrm{Zn}$ in vegetable tissue and/or, the greater biomass yield. Comparing the amount of exported nutrients by the above ground part with those added to the soil by application of $40 \mathrm{tha}^{-1}$ of SS, the inputs were positive, except for B and K, which were negative.

Keywords: Sacharum spp. Trace-metal. Acid phosphatase. Agricultural disposal of waste. Environmental impact. 


\section{INTRODUÇÃO}

A cidade moderna oferece uma série de facilidades pela intensificação no uso de tecnologias, o que a torna atrativa para a população, podendo ocorrer um crescimento demográfico desordenado. A adoção de tecnologia intensiva, entretanto, tem trazido consigo a geração de poluentes, o que, aliado à deficiência no planejamento urbano, submete o homem a uma condição cada dia mais artificial, tendo reduzido contato com a natureza, deixando-o mais exposto às doenças e ao estresse. Desta situação surge à necessidade de se evitar e, ou, atenuar o impacto antrópico, a exemplo da contaminação dos rios, e recuperar os recursos naturais já comprometidos. No tratamento das águas servidas nas grandes cidades, origina-se o lodo de esgoto (LE), o qual suscita as seguintes questões: onde depositá-lo? Como usá-lo, sem oferecer impacto negativo sobre a qualidade ambiental?

Várias são as opções para a disposição final do LE, dentre as quais se destaca o simples descarte em aterros sanitários, a incineração, a conversão em óleo combustível, o reuso industrial, o tratamento no solo (landfarming) e o uso agrícola e florestal (ABREU JUNIOR et al., 2005; SILVA, 1995). A alternativa agrícola para disposição do lodo de esgoto é a mais promissora, por oferecer além de uma alternativa segura e viável economicamente para seu descarte, traz consigo uma série de vantagens associadas ao seu emprego agrícola por se tratar de fonte de nutrientes, matéria orgânica e um condicionador de propriedades dos solos (ABREU JUNIOR et al., 2008; BETTIOL e CAMARGO, 2006; ABREU JUNIOR et al., 2005; SILVA, 1995; BETTIOL et al., 1983).

A sustentabilidade da produção da cultura de cana-de-açúcar só pode ser atingida quando os nutrientes no sistema canavieiro têm balanço nulo ou positivo. É essencial conhecer, portanto, as perdas de nutrientes mais importantes no agrossistema. Dentre as possíveis causas de saída de nutrientes do solo, merecem destaque as quantidades exportadas pelos colmos que variam em $\mathrm{g} \mathrm{t}^{-1}$, de: 740 a 1100 de N; 27 a 62 de P; 820 a 3000 de K; 89 a 213 de Ca; 109 a 220 de Mg; 116 a 359 de S; 0,9 a 2,1 de $\mathrm{Zn} ; 0,5$ a 0,9 de $\mathrm{Cu} ; 19$ a 36 de Fe; 8 a 21 de $\mathrm{Mn}$ e 9 a 35 de $\mathrm{Al}$ (PRIMAVESI et al., 1992; ORLANDO FILHO, 1983).

Os nutrientes exportados pelos colmos podem ser compensados pela adição de diversos resíduos, tais como o LE, e por técnicas de cultivo que maximizam a atividade biológica e mantenham a fertilidade e a produtividade do solo. A composição química do LE é bastante heterogênea em função das matérias-primas que o constituem, isto é, depende basicamente da origem dos resíduos serem mais domésticos ou industriais (FORTUNY e FULLER, 1979; SOMMERS, 1977). Quando o LE é proveniente de estações de tratamento das águas servidas, com predominância de esgotos domésticos sobre os industriais oriundos de despejos clandestinos, os níveis de $\mathrm{Cd}, \mathrm{Cu}, \mathrm{Mo}, \mathrm{Ni}, \mathrm{Zn}$ e $\mathrm{Pb}$, além de $\mathrm{Mn}, \mathrm{Fe}, \mathrm{Al}, \mathrm{Cr}$ e $\mathrm{Hg}$, entre outros menos freqüentes, permanecem dentro das faixas aceitáveis para o seu uso agronômico (ABREU JUNIOR et al., 2008; BETTIOL e CAMARGO, 2006; 
ABREU JUNIOR et al., 2005; TSUTIYA, 2002; GALLOWAY e JACOBS, 1977). Desta forma, poderá ser utilizado na agricultura, com segurança, o lodo que, devidamente condicionado biológica e fisicamente, atender à Resolução $\mathrm{n}^{\mathrm{o}} 375$ do CONAMA que legisla sobre o uso de lodo de esgoto na agricultura no Brasil (BRASIL, 2006).

Em nosso país o uso do LE como fertilizante já foi testado em culturas como soja, milho, arroz feijão e outras (BETTIOL e CAMARGO, 2006; ABREU JUNIOR et al., 2005; BETTIOL e CARVALHO, 1982; GUSHI et al., 1982;). Quanto à dose adequada deve considerar os valores adequados ambientalmente. Berton et al. (1989) e Cunningham et al. (1975) verificaram efeitos positivos na cultura do milho, quando empregaram doses de LE mais elevadas, na faixa de 40 a $80 \mathrm{tha}^{-1}$, na base seca. $\mathrm{O}$ mesmo fato se repetiu ainda para a cultura de sorgo granífero, quando aplicadas às doses de 30 e $60 \mathrm{tha}^{-1}$ de LE, na base seca (DIAS, 1994). Ros et al. (1993) verificaram que o LE aplicado em doses de 80 e $160 \mathrm{tha}^{-1}$, com $92 \%$ de umidade, pode elevar a produtividade em matéria seca, sendo que o efeito pode se dar de dois modos distintos: imediato sobre a produção de milheto e residual na produção de grãos de aveia, em associação com ervilhaca.

Para a cana-de-açúcar, Marques (1990) avaliou as variáveis tecnológicas e composição em N, P e K do caldo de cana-de-açúcar adubada com doses crescentes de LE, aplicado na cana-planta e na cana-soca, comparativamente com a testemunha e a fertilização química NPK. Para cana-planta, esse autor verificou que a aplicação de 4 a $8 \mathrm{tha}^{-1}$ de LE, com $72 \%$ de umidade, não teve efeito na concentração de $\mathrm{N}$ total no caldo. Aumentando as doses de LE para 16 e $32 \mathrm{t} \mathrm{ha}^{-1}$, porém, houve redução nos teores desse nutriente no caldo em toda a safra. Silva et al. (2000 e 1996) e todavia, destacaram que é importante o efeito residual do LE, aplicado no plantio da cana-planta, quanto ao fornecimento de $\mathrm{N}$ à cana-soca foi pequeno, indicando está pratica restringiu-se à cana-planta. Este aspecto pode ser comprovado, pois quando o LE foi reaplicado ao solo houve aumento de concentração de $\mathrm{N}$ no caldo da canasoca, em relação ao tratamento testemunha. Verificou-se ainda que o maior acúmulo de P no caldo foi obtido pela aplicação de $8 \mathrm{t} \mathrm{ha}^{-1}$ de LE (MARQUES et al., 2007a).

Chiba (2005), aplicando até $8,2 \mathrm{tha}^{-1}$ de LE (base seca) em cana-planta, em combinação com adubo fosfatado, e $16 \mathrm{t} \mathrm{ha}^{-1}$ de LE em cana-soca, em combinação com adubo nitrogenado, verificou que o LE pode substituir até $25 \%$ do adubo fosfatado na cana-planta e $100 \%$ do adubo nitrogenado na cana-soca. MARQUES et al. (2007a) também verificaram benefícios do aproveitamento do LE na cana-deaçúcar quando comparado a aplicação de fertilizantes minerais. Segundo esses autores, a associação do LE com o adubo mineral, nas condições em que foi conduzido o experimento, permitiu a economia de metade da adubação mineral recomendada, mantendo-se a produtividade, as características químicas do solo, em sua maioria, e as características tecnológicas da cana-de-açúcar.

O LE não é um eficiente fornecedor de potássio à cana-de-açúcar (SILVA et al., 1996; MARQUES, 1990), assim a aplicação do LE deve ser obrigatoriamente 
complementada com uma fonte de potássio (ABREU JUNIOR et al., 2008). Franco (2003) observou que aplicação de LE, como fonte de N, em combinação com vinhaça, como fonte de $\mathrm{K}$, foi tão eficientes quanto as fontes minerais desses dois nutrientes (uréia e $\mathrm{KCl}$ ) na produtividade e qualidade industrial da cana-planta (SP813250). No $2^{\circ}$ corte ( $1^{a}$ cana-soca), Tasso Junior et al. (2007) observaram que as maiores produtividades foram encontradas quando se empregou LE complementado com $\mathrm{KCl}\left(106,6 \mathrm{t} \mathrm{ha}^{-1}\right)$, sendo esses valores da mesma ordem de grandeza daqueles obtidos com a fertilização mineral $\left(105,6 \mathrm{t} \mathrm{ha}{ }^{-1}\right)$. Para o $3^{\circ}$ e $4^{\circ}$ cortes, Camilotti et al. (2006) não encontraram diferenças na produtividade da cana-de-açúcar, adubada com LE + KCL e vinhaça + uréia. No $5^{\circ}$ corte, Nogueira et al. (2007) concluíram que o LE ou a vinhaça complementada apresentaram desempenho comparáveis à fertilização mineral.

Do ponto de vista tecnológico, Marques et al. (1994), Marques (1990) e Silva et al. (1996), verificaram que o uso de LE não causou dificuldades adicionais para a cultura canavieira, pois não houve efeito do LE na pureza do caldo, embora tenha havido pequenas diminuições no valor do Brix e da pol.

Não obstante aos benefícios evidentes, patógenos e compostos orgânicos e inorgânicos potencialmente tóxicos podem estar presentes no LE e poluir o ambiente e afetar cadeia alimentar. Além de haver certo questionamento pelos próprios agricultores, o potencial de poluição do ambiente tem sido alvo constante de críticas e fator de restrição do uso agrícola do LE por parte dos agentes de controle de poluição ambiental (ABREU JUNIOR et al., 2005, 2008; BETTIOL e CAMARGO, 2006).

Marques et al. (2007b), estudando a aplicação de 0, 10, 20 e $40 \mathrm{t} \mathrm{ha}^{-1} \mathrm{LE}$ (base seca), verificaram aumento nas concentrações de $\mathrm{Cr}, \mathrm{Ni}, \mathrm{Pb}$ e $\mathrm{Zn}$ no solo (linha e entrelinha) sob cultivo de cana-de-açúcar, sendo, a dose de $40 \mathrm{tha}^{-1}$ a que promoveu as maiores concentrações de metais-traços no solo. Os valores encontrados estão abaixo das concentrações máximas aceitáveis de metais-traços nos solos tratados com LE, de acordo com as normas da CETESB (2005a). A baixa ocorrência ou mesmo a ausência de metais nas partes aéreas de plantas de cana-de-açúcar foi relatada por Silva et al. (2000), os quais, analisando plantas cultivadas em solos que receberam, no ano anterior, lodo de esgoto nas doses de 20;40 e $80 \mathrm{tha}^{-1}$, não detectaram a presença de metais nas partes aéreas das plantas, porém verificaram o acúmulo desses elementos nas raízes. Camilotti et al. (2007) estudando a disponibilidade de metais pesados $(\mathrm{Cd}, \mathrm{Cr}, \mathrm{Ni}$ e $\mathrm{Pb})$ no solo e nas partes (colmos, folhas e palmitos) das plantas de cana-de-açúcar, verificaram que as doses de LE não apresentaram, após três aplicações anuais sucessivas, potencial de contaminação do sistema solo-cana.

Verifica-se, portanto, que os resultados disponíveis na literatura relatam o emprego de LE na cultura canavieira com enfoque sobre os aspectos agrotecnológicos, havendo poucas referências aos seus efeitos na nutrição da planta, transferência de metais-traços e a qualidade produtos agrícolas. Isto justifica, portanto, a execução do presente trabalho, no qual se procurou, em condições de campo, avaliar os efeitos da aplicação do LE no solo, com e sem complementação 
com adubo mineral NPK, sobre a nutrição e produtividade da cana de 18 meses, O objetivo foi caracterizar o efeito fertilizante do resíduo e os possíveis impactos ambientais, os aspectos de equilíbrio energético e a exportação de metais-traços nos colmos.

\section{MATERIAL E MÉTODOS}

O solo pertence ao grande grupo Argissolo Vermelho-Amarelo distrófico, abrupto a moderado, textura arenosa/média, unidade Serrinha (PVA) (EMBRAPA, 1999), equivalente a Arenic Abruptic Paleudult (ESTADOS UNIDOS, 1999). As características químicas do solo antes da instalação do experimento, nas camadas de 0-20 cm e $20-50 \mathrm{~cm}$ de profundidade, estão apresentadas na (Tabela 1). Pela interpretação dos resultados para fins de fertilidade do solo, antes da instalação do ensaio, verificou-se que a camada de $0-50 \mathrm{~cm}$ de profundidade era homogênea, apresentava valor de $\mathrm{pH}$, em $\mathrm{CaCl}_{2}$, baixo, teores de matéria orgânica baixo e de nutrientes $(\mathrm{Ca}, \mathrm{Mg}, \mathrm{K}$ e $\mathrm{P})$ muito baixos, acidez total $(\mathrm{H}+\mathrm{Al})$ elevada, soma de bases (SB) e saturação por bases (V) baixa (SILVA, 2009).

Tabela 1 - Propriedades químicas do solo no local do experimento.

\begin{tabular}{|c|c|c|c|c|c|c|c|c|c|c|}
\hline Profundidade & M.O & $\mathrm{pH}$ & $\overrightarrow{\mathrm{Ca}}$ & & $\mathrm{Mg}^{2+}$ & $\mathrm{K}^{+}$ & $\mathrm{H}+\mathrm{A}$ & SB & $\mathrm{T}$ & $\mathrm{P}$, resina \\
\hline $\mathrm{cm}$ & $\mathrm{gkg}^{-1}$ & $\mathrm{CaCl}_{2}$ & & & \multicolumn{5}{|c|}{$\mathrm{mmol}_{\mathrm{c}} \mathrm{dm}^{3}$ de Terra } & $\mathrm{mg} \mathrm{dm}{ }^{-3}$ \\
\hline $0-20$ & 13,5 & 4,3 & 5,2 & & 1,8 & 1,6 & 24,5 & 8,6 & 33,1 & 4,5 \\
\hline \multirow[t]{5}{*}{$20-50$} & 7,0 & 4,4 & 6,8 & & 2,0 & 0,8 & 20,0 & 9,6 & 29,6 & 3,0 \\
\hline & & fundic & de & $\mathrm{Cd}$ & $\mathrm{Cr}$ & $\mathrm{Cl}$ & $\mathrm{Mn}$ & $\Gamma$ & $\mathrm{Pb}$ & \\
\hline & & $\mathrm{cm}$ & \multicolumn{7}{|c|}{$\mathrm{mgdm}^{-3}$ de terra (DTPA) } & \\
\hline & & $0-20$ & & 0,05 & 0,06 & 0 , & 30 & & 0,97 & \\
\hline & & $20-50$ & & 0,02 & 0,01 & 0 & 32 & & 0,75 & \\
\hline
\end{tabular}

O LE foi aplicado no fundo do sulco de plantio nas doses de 0,20 e $40 \mathrm{tha}^{-1}$, na base de material úmido, com $620 \mathrm{~g} \mathrm{~kg}^{-1}$ de água. $\mathrm{O} \mathrm{N}, \mathrm{P}$ e $\mathrm{K}$ foram aplicados nas doses de 60, 34 e $83 \mathrm{~kg} \mathrm{ha}^{-1}$, respectivamente. Os tratamentos foram constituídos pela combinação de três doses de LE com e sem adubos NP, NK, PK e NPK. O experimento foi instalado em delineamento em blocos ao acaso, com 15 tratamentos e 3 repetições, totalizando 45 parcelas.

O LE proveniente de E.T.A Barueri foi analisado em extrato de água régia (digerido com auxílio de microondas) em métodos descrito em Silva (2009), obtendose os seguintes resultados, em $\mathrm{g} \mathrm{kg}^{-1}$ (na base de matéria seca): $\mathrm{C}=71 ; \mathrm{N}=22 ; \mathrm{P}=10$; 
$\mathrm{Al}=2,0 ; \mathrm{Ca}=11,5 ; \mathrm{Mg}=3,5 ; \mathrm{K}=2,0^{*} ; \mathrm{S}=10 ; \mathrm{e} \mathrm{Fe}=50 ; \mathrm{e}$, em $\mathrm{mg} \mathrm{kg}^{-1}: \mathrm{Cu}=905$, $\mathrm{Mn}=505, \mathrm{Cd}=25, \mathrm{Cr}=64^{*}, \mathrm{Ni}=445, \mathrm{~Pb}=265$ e $\mathrm{Zn}=1880$ e $\mathrm{pH}=10$.

A avaliação inicial do perfilhamento das plantas ocorreu aos 86 dap. Para avaliar os efeitos do LE no sistema solo-planta, coletaram-se amostras de solo aos 146 dias após plantio (dap). As amostras de solo, compostas de 9 subamostras por parcela, foram retiradas na camada de 0 a $20 \mathrm{~cm}$, na próximo a linha de cana, correspondente ao sulco de plantio. As amostras de terra foram analisadas pelo sistema IAC (SILVA, 2009), determinando-se S por turbidimetria, após extração com $\mathrm{CaCl}_{2} 1,5 \mathrm{~g} \mathrm{~kg}^{-1}$. Os metais pesados $\mathrm{Cr}, \mathrm{Cd}, \mathrm{Cu}, \mathrm{Fe}, \mathrm{Mn}, \mathrm{Pb}$ e $\mathrm{Zn}$ foram extraídos do solo por solução de DTPA, pH 7,3 (relação=2:1), e determinados em espectrômetro de emissão atômica em plasma (ICP-OES). As amostras de folhas +1 foram colhidas aos 146 dap, visando à determinação da atividade de fosfatase ácida e dos teores totais dos nutrientes e metais-traços, após digestão nítrico-perclórica e sulfúrica. $\mathrm{Na}$ colheita final, amostrou-se a parte aérea, mediu-se a produção de biomassa e determinaram-se as variáveis tecnológicas (Brix, Pol, AR, fibra) e os teores totais de $\mathrm{N}$ pelo método de Kjeldahl, em extratos da digestão sulfúrica, e de $\mathrm{P}, \mathrm{Ca}, \mathrm{Mg}, \mathrm{K}, \mathrm{S}$, $\mathrm{Zn}, \mathrm{B}, \mathrm{Cu}, \mathrm{Se}, \mathrm{Cd}, \mathrm{Cr}, \mathrm{Ni}$ e $\mathrm{Pb}$ por ICP-OES, em extratos da digestão nítricoperclórica (SILVA, 2009).

Para determinação da atividade da fosfatase ácida, tomaram-se $100 \mathrm{mg}$ de fragmentos de $3 \mathrm{~mm}$ de largura de limbo foliar, de material fresco, recém-coletado, correspondendo à folha +1 , contada do "colarinho", que foram incubados com $8 \mathrm{~mL}$ de paranitrofenilfosfato $0,25 \mathrm{mmol} \mathrm{L}^{-1}$ em tampão acetato de sódio $0,1 \mathrm{~mol} \mathrm{~L}^{-1}$ $(\mathrm{pH}=4,0)$. Após incubação de 20 minutos a $30{ }^{\circ} \mathrm{C}, 5 \mathrm{~mL}$ de mistura de reação foram alcalinizados com $2 \mathrm{~mL}$ de $\mathrm{NaOH} 2 \mathrm{~mol} \mathrm{~L}^{-1}$, estimando-se colorimetricamente (a $410 \mathrm{~nm}$ ) a quantidade de paranitrofenol formado com auxílio de reta padrão estabelecida. A atividade enzimática foi expressa em moles de substrato hidrolisados por hora por grama de tecido foliar fresco $\left(\mathrm{mol} \mathrm{h}^{-1} \mathrm{~g}^{-1}\right)$ (SILVA e BASSO, 1993).

Os resultados experimentais obtidos foram avaliados através de análise da variância em delineamento em blocos ao acaso em esquema fatorial para as causas de variação (LE, adubo químico e blocos), procedendo-se um contraste inicial entre médias para os fatores fórmula mineral (5) e a interação com a complementação com doses de LE (3) empregando-se o Teste de Tukey a 5\% de probabilidade e, para avaliar o efeito de doses de LE utilizou-se modelo de regressão polinomial de $1^{\circ}$ e $2^{\circ}$ graus para cada época complementação possível com adubo mineral. Para estudar os efeitos da aplicação do LE sobre os sobre os atributos do solo e da planta que causaram alterações nas produções de biomassa e na produtividade em açúcar, utilizaram-se a seleção de índices edáficos e biológicos variáveis nos métodos de seleção de regressão linear múltipla, adotando-se como procedimentos encontrados no software SANEST, versão 3.0 como a técnica de "stepwise" e a teoria de base pormenorizada em Mattioli (1983). 


\section{RESULTADOS E DISCUSSÃO}

A importância do fósforo no desenvolvimento radicular da cana-de-açúcar e seu efeito no aumento do perfilhamento e do crescimento do colmo é bastante conhecida na literatura (CESAR et al., 1990). Tal fato foi observado pelo coeficiente de correlação (valor $r$ ) entre o perfilhamento inicial da cultura que está diretamente relacionado ao teor de fósforo no solo $\left(\mathrm{r}=0,81^{* *}\right)$ e de outros nutrientes associados ao metabolismo energético da cana-de-açúcar, a exemplo do $\mathrm{Cu}\left(0,69^{*}\right)$ e do $\mathrm{Zn}$ $\left(0,74^{* *}\right)$. A probabilidade estatística no teste $\mathrm{F}$ para os coeficientes das correlações da atividade enzimática da fosfatase foram de 5 e $1 \%$, ou seja, de $p<0,05$ e $p<0,01$ respectivamente.

Para melhor entender o processo de perfilhamento da planta com o equilíbrio metabólico energético-fosfórico e as variáveis associadas ao estado nutricional da cana-de-açúcar, adotou-se o monitoramento da atividade da enzima fosfatase ácida na folha, haja vista que atividade desta enzima é aumentada na deficiência de fósforo (SILVA e BASSO, 1993). Teoricamente, portanto, plantas cultivadas em solos com deficiência de $\mathrm{P}$ e, ou, de $\mathrm{Cu}$ e $\mathrm{Zn}$, teriam valores maiores de atividade dessa enzima. $\mathrm{O}$ LE, corrigindo o baixo teor original de $\mathrm{P}$ no solo (Tabela 1), deve possibilitar um melhor perfilhamento inicial, refletindo mais tarde, no caso da cana-de-açúcar, em uma boa produção de biomassa da parte aérea.

Além do aspecto de fornecimento de nutrientes ao solo, a adição do LE, devido a sua ação alcalina, corrigiu a acidez do solo, refletindo em maior perfilhamento, o que pode ser constatado pelas correlações positivas entre as variáveis (Tabela 2).

Tabela 2 - Valor significativo de correlação entre perfilhos $/ \mathrm{m}$, colmos $/ \mathrm{m}$ e o fator perfilhamento (FP) com teores de algumas espécies químicas no solo, amostrados aos 146 dap.

\section{Parâmetros de Planta}

Variáveis de solo correlacionadas(r)

Número de perfilhos/m $\mathrm{pH}\left(0,75^{* *}\right), \mathrm{H}+\mathrm{Al}\left(-0,74^{* *}\right)$. SB $\left(0,78^{* *}\right), \mathrm{CTC}\left(0,74^{* *}\right)$ e V\%

$$
\begin{gathered}
\left(0,87^{* *}\right), \mathrm{Ca}\left(0,60^{* *}\right), \mathrm{Mg}\left(0,65^{* *}\right), \mathrm{P}\left(0,81^{* *}\right), \mathrm{Cu}\left(0,69^{*}\right), \mathrm{Zn} \\
\left(0,74^{* *}\right), \mathrm{Ni}\left(0,68^{*}\right) \text { e B }\left(0,54^{*}\right) .
\end{gathered}
$$

Número de colmos/m $\quad \mathrm{pH}\left(0,73^{* *}\right), \mathrm{H}+\mathrm{Al}\left(-0,68^{*}\right), \mathrm{SB}\left(0,74^{* *}\right), \mathrm{CTC}\left(0,76^{* *}\right)$ e V\%

$$
\begin{gathered}
\left(0,80^{* *}\right), \mathrm{Ca}\left(0,63^{*}\right), \mathrm{P}\left(0,75^{* *}\right), \mathrm{Cu}\left(0,64^{* *}\right), \mathrm{Fe}\left(0,54^{*}\right), \mathrm{Zn} \\
\left(0,68^{* *}\right), \mathrm{Ni}\left(0,69^{* *}\right) \text { e B }\left(0,65^{* *}\right) .
\end{gathered}
$$

Fator Perfilhamento

$\mathrm{PH}(0,74 * *), \mathrm{H}+\mathrm{Al}\left(-0,76^{* *}\right), \mathrm{SB}\left(0,75^{* *}\right), \mathrm{CTC}(0,70 * *)$ e V\% (n.perf./n.c)

$$
\left(0,84^{* *}\right), \mathrm{Ca}\left(0,56^{* *}\right), \mathrm{Mg}\left(0,66^{*}\right), \mathrm{P}\left(0,80^{* *}, \mathrm{Cu}\left(0,66^{* *}\right), \mathrm{Fe}\right.
$$

$$
\left(0,50^{*}\right), \mathrm{Zn}\left(0,73^{* *}\right), \mathrm{Ni}\left(0,66^{* *}\right), \mathrm{B}\left(0,49^{*}\right),
$$

\footnotetext{
$* \mathrm{e}^{* *}=$ significativos a 5 e $1 \%$ no teste $\mathrm{F}$.
} 
Outro aspecto, não menos importante a ser considerado, é que o LE aplicado no fundo do sulco de plantio pode, além de propiciar melhor disponibilidade de água, favorecer ainda a formação de melhor estrutura física do solo (SILVA et al., 1996; MELO et al.,1997), o que, também, refletiu no perfilhamento (Figura 1a).

$\mathrm{Na}$ avaliação inicial do perfilhamento, verificou-se que as médias do número de perfilhos (Figura 1a), evidenciam clara resposta à adubação com $P$, seja proveniente do LE, seja pelo adubo mineral. Verificou-se, entretanto, que na ausência de LE, o perfilhamento foi incrementado pelo adubo mineral, mas não foi igual foi maior quando o LE foi adicionado.

(a)

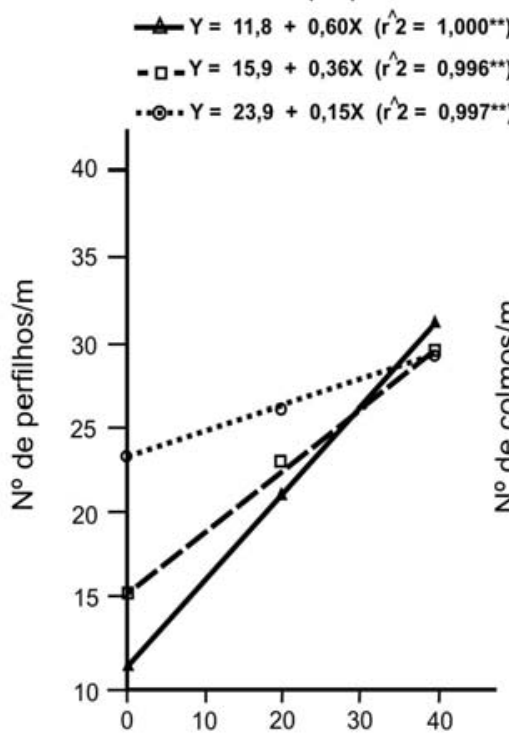

(b)

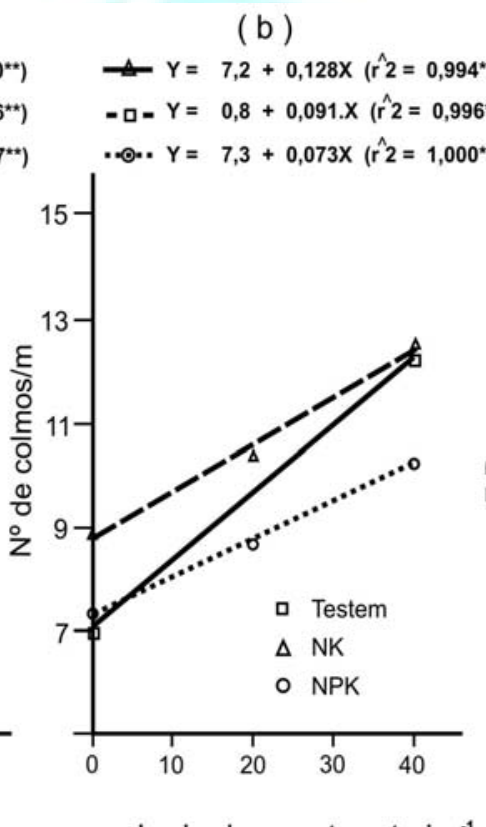

(c)

$\stackrel{-}{-} Y=1,73+0,041 X\left(\hat{r} 2=0,778^{* *}\right)$

$-\square-Y=1,86+0,024 X\left(\hat{r} 2=0,878^{* *}\right)$

.๑. $Y=2,70+0,008 X\left(\hat{r} 2=0,973^{* *}\right)$

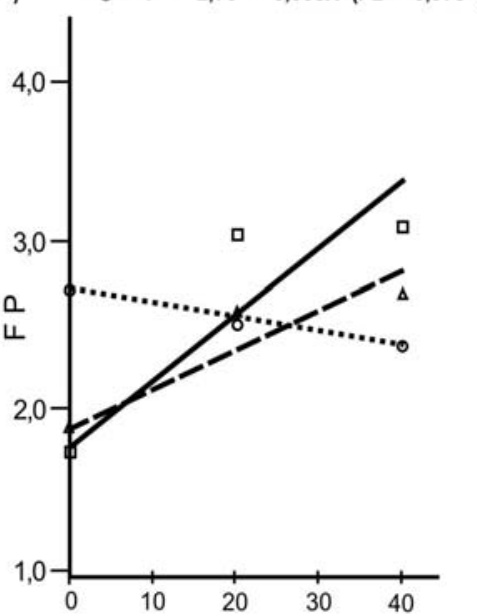

Lodo de esgoto - $\mathrm{t}$. ha ${ }^{-1}$

Figura 1. Influência da aplicação de doses de lodo de esgoto ao solo, no perfilhamento (a), no número de colmos industrializáveis por metro (b) e do fator perfilhamento (c) na cana-planta. ** Significativo a $1 \%$ de probabilidade, no teste $\mathrm{F}$.

A atividade da fosfatase $\left(\mathrm{mol} \mathrm{g}^{-1} \mathrm{~h}^{-1}\right)=2,938+0,071 . \mathrm{P}-0,335 . \mathrm{Cu}-0,003 . \mathrm{S}+$ 14,01.K - 8,43.B (Equação 1), $\mathrm{R}^{2}=65,25^{* *} ; \mathrm{p}<0,01$, sendo os teores de $\mathrm{P}$, extraído pelo método da resina, e de $\mathrm{Cu}, \mathrm{S}, \mathrm{K}$ e B, extraídos com DPTA expressos em $\mathrm{mg} \mathrm{dm}{ }^{-}$ 3 de solo.

Tal equação foi altamente significativa, explicando $65 \%$ da atividade da fosfatase na folha+1, demonstrando que em condições de campo a atividade da enzima é função não apenas do teor de $\mathrm{P}$ do solo, mas também de outros íons presentes, que podem atuar como ativadores e/ou co-fatores da enzima. Cabe ressaltar que o aumento do perfilhamento pode ser explicado também pelo efeito indireto do LE na correção da acidez (CTC, SB, pH e V) que aumenta a disponibilidade dos nutrientes citados pelo efeito da elevação do $\mathrm{pH}$ do solo, que parece ser o caso do $\mathrm{Ca}$, $\mathrm{P}$ e do $\mathrm{Zn}$ (Tabela 2). Isto pode ter promovido melhor equilíbrio nutricional na parte 
aérea do vegetal (Tabela 3 ), assim como provavelmente favoreceu o desenvolvimento do próprio radicular, como constataram Silva et al. (1996).

Tabela 3 - Valor significativo de correlação entre os perfilhos $/ \mathrm{m}$, colmos/m e o fator perfilhamento (FP) com os teores foliares de nutrientes, aos 146 dap.

\begin{tabular}{cc}
$\begin{array}{c}\text { Parâmetros de } \\
\text { Planta }\end{array}$ & Variáveis nutricionais correlacionadas(r) \\
\hline $\begin{array}{c}\text { Número de } \\
\text { perfilhos } / \mathrm{m}\end{array}$ & $\mathrm{N}\left(0,74^{* *}\right), \mathrm{P}\left(0,78^{* *}\right), \mathrm{Ca}\left(0,79^{* *}\right), \mathrm{Fe}\left(-0,61^{*}\right), \mathrm{Mn}\left(0,65^{*}\right), \mathrm{Zn}$ \\
& $\left(0,50^{*}\right), \mathrm{Ni}\left(0,65^{*}\right)$. \\
Número de colmos/m & $\mathrm{P}\left(0,52^{* *}\right), \mathrm{Ca}\left(0,66^{* *}\right), \mathrm{Fe}\left(0,62^{* *}\right), \mathrm{Mn}\left(0,72^{* *}\right), \mathrm{Ni}\left(0,59^{* *}\right), \mathrm{B}$ \\
$\left(0,52^{*}\right), \mathrm{S}\left(0,70^{* *}\right)$ e $\mathrm{Al}\left(-0,74^{* *}\right)$. \\
$\begin{array}{c}\text { Fator Perfilhamento } \\
\text { (n.perf./n.c) }\end{array}$ & $\mathrm{N}\left(0,73^{* *}\right), \mathrm{P}\left(0,79^{* *}\right), \mathrm{Ca}\left(0,77^{* *}\right), \mathrm{Fe}\left(-0,63^{*}\right), \mathrm{Zn}\left(0,51^{*}\right), \mathrm{Ni}$ \\
\hline
\end{tabular}

$\mathrm{e}^{* *}=$ significativos a 5 e $1 \%$ no teste $\mathrm{F}$.

Tendo por base os dados do número de perfilhos e das observações visuais no campo, procedeu-se ao agrupamento de perfilhos em três grupos distintos. O primeiro grupo, de baixo valor de contagem foi constituído pela testemunha e por aqueles tratamentos sem adição de fosfato. Observou-se, nas plantas cultivadas destes tratamentos, carência acentuada de $\mathrm{P}$, caracterizada pela coloração de verde-azulada até roxa nas folhas e pelo menor crescimento. Este fato era previsível, haja vista que o teor original de $\mathrm{P}$ do solo extraído pela resina muito baixo, e o teor foliar abaixo do nível adequado (SILVA e BASSO, 1993).

No segundo grupo, encontram-se os tratamentos que combinaram adubos minerais com $20 \mathrm{t} \mathrm{ha}^{-1}$ de LE. Verificou-se que, quando se aplicou o LE sem suplementação de $\mathrm{N}$, houve amarelecimento das folhas mais velhas, sintoma característico da deficiência de N. Isto ocorreu, possivelmente, devido à imobilização do $\mathrm{N}$ nativo do solo, em fase inicial de mineralização do LE recém-adicionado. Essa imobilização de $\mathrm{N}$ do solo, todavia, não deve ter sido muito intensa porque a relação $\mathrm{C} / \mathrm{N}$ original do LE era inferior a cinco e no solo, aos 272 dap e a relação $\mathrm{C} / \mathrm{N}$ era de $1: 16$.

No terceiro grupo se encontram os tratamentos com combinações de adubos minerais com $40 \mathrm{t} \mathrm{ha}^{-1}$ de LE, tendo sido observadas plantas com deficiência de $\mathrm{K}$, que pode ter sido induzida pelo efeito antagônico deste elemento com o $\mathrm{Ca}$ e $\mathrm{Mg}$, que tiveram seus teores no solo sensivelmente elevados pelo LE, fato também constado por Mulchi et al., (1987), Bettiol et al. (1983) e Carvalho (1982).

Pela diagnose foliar, pode-se constatar que, apesar de o LE conter $\mathrm{N}$, não houve efeito marcante na nutrição nitrogenada na cana planta. $O$ fato da cana-planta não responder à adubação nitrogenada não surpreende, devido à fixação biológica na 
cana no inicio do cultivo, pois isto é comum ocorrer quando do cultivo desta gramínea nos solos paulistas, o que se inverte na soqueira (ORLANDO FILHO, 1983) Marques (1990) não encontrou efeito de doses de LE nos teores de N do caldo de cana-planta. Os demais nutrientes que tiveram seus teores no solo influenciados pela aplicação de LE, também tiveram modificado os seus teores foliares. Houve aumentos nos teores foliares de todos os elementos avaliados $(\mathrm{Ca}, \mathrm{P}, \mathrm{Mg}, \mathrm{S}, \mathrm{Zn}, \mathrm{B}$, $\mathrm{Cu}, \mathrm{Mn}, \mathrm{Se}, \mathrm{Ni}$ e $\mathrm{Cd}$ ), exceto para o K e Fe (Tabela 4). Houve diminuição no teor de $\mathrm{K}$ na folha pela adição de LE. São duas as possíveis explicações para o fato. A primeira se deve à diminuição no teor de $\mathrm{K}$ no solo pela ação de diluição no complexo coloidal pela simples adição de LE como fonte de cálcio e a segunda, devido ao antagonismo na absorção entre este e o Ca e Mg (RAIJ et al, 1996), os quais foram fornecidos pelo LE e liberados no solo. No caso do Fe, houve aumento no seu teor extraído do solo, pelo DTPA, com as doses de LE, mas seu teor sofreu redução nas folhas, conforme aumentou a dose deste resíduo (Tabela 4). A explicação possível é o fato de o Fe se acumular nas raízes, conforme constatou Dias (1994) para o sorgo granífero.

Tabela 4 - Influência de doses de lodo de esgoto aplicado $\left(\mathrm{LE}=\mathrm{x}\right.$, em $\mathrm{t} \mathrm{ha}^{-1}$ ) sobre os teores foliares de nutrientes e de metais pesados, avaliada por regressão linear, aos 146 dias, em mg kg-1.

\begin{tabular}{|c|c|c|c|c|c|}
\hline \multirow{2}{*}{ Elemento } & \multirow{2}{*}{$\begin{array}{c}\text { Equação linear } \\
(\mathbf{Y}=\mathbf{a}+\mathbf{b . X})\end{array}$} & \multirow{2}{*}{$\mathrm{R}^{2}(\%)$} & \multicolumn{3}{|c|}{ Valores observadores $-\mathrm{t} \mathrm{ha}^{-1}$} \\
\cline { 4 - 6 } & & & 00 & 20 & 40 \\
\hline Zinco & $\mathrm{Y}=8,30+0,125 . \mathrm{X}$ & $99,25^{* *}$ & 7,2 & 10,8 & 13,4 \\
\hline Manganês & $\mathrm{Y}=200,0+2,50 . \mathrm{X}$ & $92,94^{* *}$ & 200 & 271 & 294 \\
\hline Selênio & $\mathrm{Y}=6,47+0,006 . \mathrm{X}$ & $96,45^{* *}$ & 7,0 & 7,4 & 9,0 \\
\hline Níquel & $\mathrm{Y}=0,382+0,007 . \mathrm{X}$ & $92,73^{* *}$ & 0,28 & 0,51 & 0,76 \\
\hline Enxofre & $\mathrm{Y}=2,21+0,012 . \mathrm{X}$ & $98,72^{* *}$ & 2,21 & 2,42 & 2,60 \\
\hline Cobre & $\mathrm{Y}=4,78+0,017 . \mathrm{X}$ & $85,65^{* *}$ & 4,8 & 5,2 & 5,5 \\
\hline Ferro & $\mathrm{Y}=205,5-0,625 . \mathrm{X}$ & $81,20^{* *}$ & 205 & 202 & 182 \\
\hline Boro & $\mathrm{Y}=6,58+0,047 . \mathrm{X}$ & $96,42^{* *}$ & 6,2 & 7,5 & 8,2 \\
\hline Cádmio & $\mathrm{Y}=0,33+0,009 . \mathrm{X}$ & $99,85^{* *}$ & 0,35 & 0,55 & 0,74 \\
\hline Magnésio & $\mathrm{Y}=1,45+0,017 . \mathrm{X}$ & $94,24^{* *}$ & 1,22 & 1,84 & 2,21 \\
\hline Fósforo & $\mathrm{Y}=1,25+0,012 . \mathrm{X}$ & $92,31^{* *}$ & 1,25 & 1,51 & 1,64 \\
\hline Cálcio & $\mathrm{Y}=4,30+0,042 . \mathrm{X}$ & $96,68^{* *}$ & 4,20 & 5,32 & 6,05 \\
\hline Potássio & $\mathrm{Y}=11,38-0,053 . \mathrm{X}$ & $94,95^{* *}$ & 14,0 & 10,4 & 9,7 \\
\hline
\end{tabular}

**Significativo a $1 \%$ de probabilidade, no Teste $\mathrm{F}$.

Aos 146 dap, as concentrações dos nutrientes avaliados nas folhas da canaplanta da testemunha e do tratamento que recebeu $40 \mathrm{tha}^{-1}$ de LE (Tabela 4), e os níveis críticos para "suficiência" encontrados por vários autores, dispostos entre os 


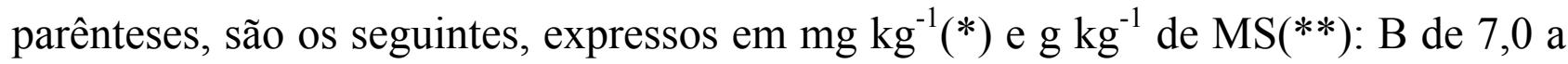
$11,5^{*}$ ( $6,0^{*}$; ORLANDO FILHO , 1983); Ca de 3,0 a 5,7** (4,3**; ORLANDO FILHO, 1983); $\mathrm{Cu}$ de 4 a 5* (4*; EL WALI e GASCHO, 1984); Fe de 202 a 177* (5 a 10*; EL WALI e GASCHO, 1984); K de 14 a 13** (12**, MALAVOLTA, 1994); Mg de 1,2 a 1,3** (1,0**; ORLANDO FILHO, 1983); Mn de 158 a 234* (> 10*; HUMBERT, 1968); P de 1,2 a 1,5** (1,5**; ORLANDO FILHO, 1983); $\mathrm{N}$ de 11 a 14** (10**; HUMBERT, 1968); S de 1,6 a 2,5** (1,3**; ORLANDO FILHO, 1983; ORLANDO FILHO et al ., 1977) e do Zn de 8 a 12* (15*; GOLDEN, 1976).

Existe relação positiva estreita entre o suprimento nutricional adequado com os números de perfilhos e de colmos por unidade de área, refletindo em correlação positiva entre o numero de perfilhos com variáveis de fertilidade do solo. Isto porque, os mesmos fatores que determinam o número de perfilhos também o fazem no número de colmos. Verifica-se visualmente nas Figuras 1a e 1b, que são semelhantes em comportamento, embora sejam diferentes os valores da ordenada, pois nem todos os perfilhos tornam-se colmos. Quando a nutrição não é adequada ou o metabolismo está desequilibrado, ou seja, há falta relativa de nutriente, nem todos os perfilhos produzem colmos, o que em última análise reflete na produtividade biológica da cana-de-açúcar. Estes aspectos ficaram evidentes na Figura 1c, onde se visualiza o fator perfilhamento, que é a razão entre o número de perfilhos/número de colmos. Assim, no tratamento NPK, praticamente todos os perfilhos produziram colmos, independente da dose de LE; mas, nos tratamentos em que o $\mathrm{P}$ foi adicionado forma de adubo mineral, não (tratamentos testemunha e NK), o fator perfilhamento foi dependente da dose de LE, evidenciando a importância do P no estabelecimento da cultura e no número final de colmos.

Verifica-se que todos os nutrientes, com exceção do $\mathrm{Ca}, \mathrm{P}$ e $\mathrm{Zn}$, independentemente do adubo NPK, estavam na planta em níveis considerados adequados, ou seja, sem limitar a produtividade. Quanto à produtividade econômica da parte aérea, expressa em $t$ ha $^{-1}$ de pol e $t h^{-1}$ de açúcar teórico recuperável (ATR) na fabricação, ou seja, o açúcar nos colmos por unidade de área observaram-se correlações positivas com os teores de $\mathrm{P}$ no solo e nas folhas, o que pode ser explicado por ele ser um nutriente importante no metabolismo energético da planta. Foi evidente que a aplicação de LE (Figura 2), promoveu uma maior produtividade de biomassa e açúcar na parte aérea, o que pode ser em parte atribuído a um melhor equilíbrio energético da planta. Em última análise, o referido equilíbrio da nutrição fosfórica parece estar correlacionado ao papel secundário do conjunto de $\mathrm{Cu}, \mathrm{Zn}$ e $\mathrm{B}$ que influem catalisando a atividade da fosfatase ácida. Tal fato mostra que as pesquisas futuras, que visam à previsão de resposta à adubação fosfatada, deveriam observar com mais atenção para as relações $\mathrm{P} / \mathrm{Zn}$ e $\mathrm{P} / \mathrm{Cu}$ na folhas +1 da cana-planta. 


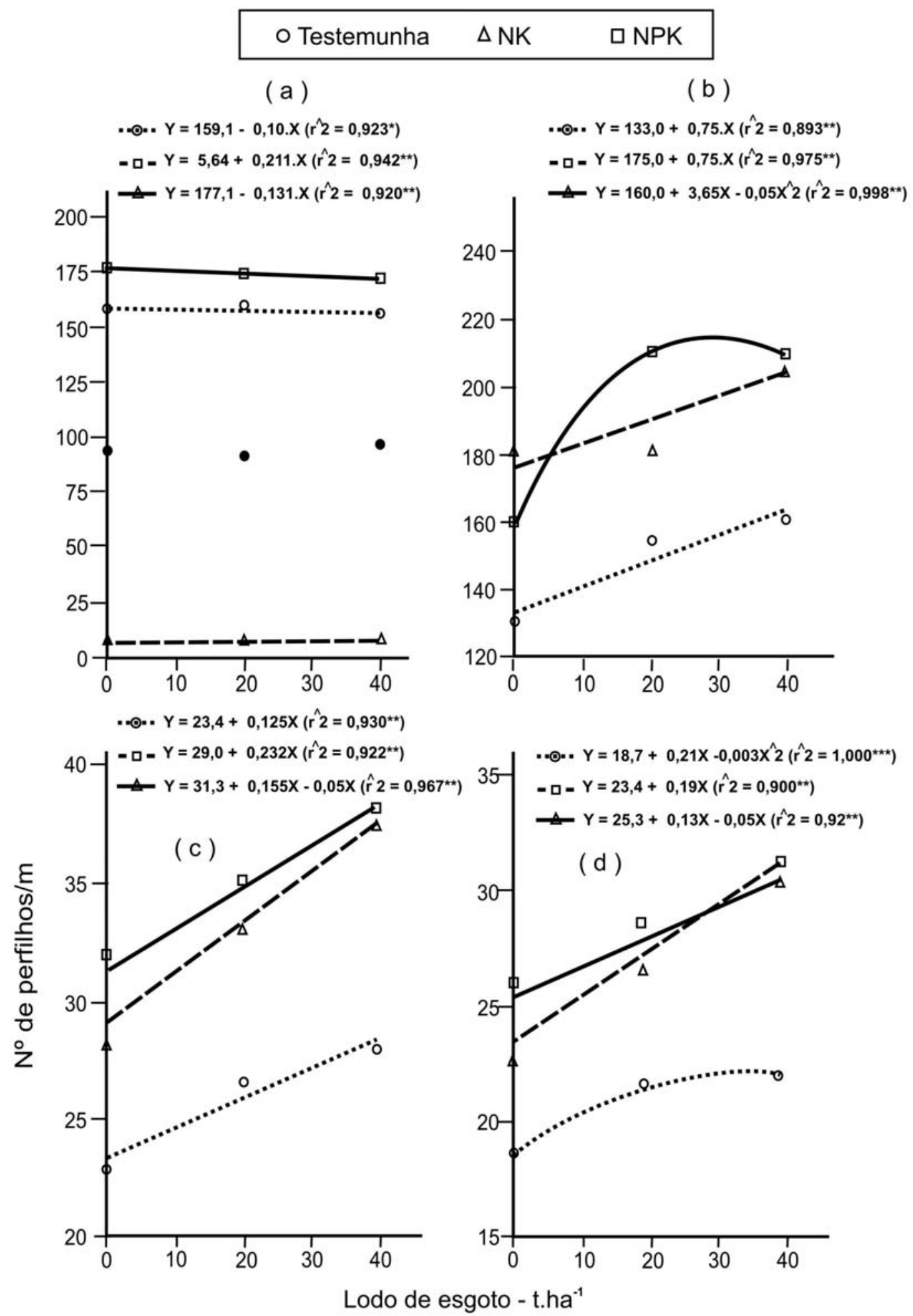

Figura 2. Influência da aplicação de doses de lodo de esgoto ao solo, nas características tecnológicas (a), produtividade de biomassa (b), de sacarose aparente (c) e de açúcar teórico recuperável (d) nos colmos de cana-planta, aos 469 dap.

$*$ e ** significativo a $5 \%$ e $1 \%$ de probabilidade no teste $\mathrm{F}$, respectivamente. 
As variáveis tecnológicas da cana-de-açúcar: Brix, pol, fibra e açúcares redutores não foram influenciadas pela aplicação do LE (Figura 2). As variações nos valores das variáveis tecnológicas foram pequenas, como também observado por Marques et al.(1994), o que resultou em estreita faixa de variação na quantidade de ATR, de 124 a $128 \mathrm{~kg} \mathrm{t}^{-1}$ de colmo de cana.

Finalmente, é necessário enfatizar que estes aspectos comentados abrangem todos os efeitos benéficos do LE sobre as produtividades da cana-de-açúcar, o que é explicado por um conjunto de melhoria na fertilidade do solo. Foi demonstrado que ainda existe interação entre o LE e a adubação química (Figuras 2b, c e d).

Quanto à composição química dos colmos, verificou-se que houve efeito da aplicação de LE ao solo $(\mathrm{p}<0,01)$ sobre as concentrações de $\mathrm{Cu}, \mathrm{Mn}, \mathrm{N}, \mathrm{P}$ e $\mathrm{S}$ (Figura 3 ). Quando se compararam os nutrientes que variaram significativamente nos colmos, através dos dados obtidos nos tratamentos testemunha e com LE na dose de 40 t.ha $^{-1}$, verificaram-se variações nos teores destes, como seguem: $\mathrm{Cu}(6,8$ a 8,6*), Mn (35 a $\left.32^{*}\right), \mathrm{N}\left(2,2\right.$ a $\left.2,5^{* *}\right), \mathrm{P}\left(0,4\right.$ a $\left.0,5^{* *}\right)$ e $\mathrm{S}\left(0,65\right.$ a $\left.0,93^{*}\right)$, onde expressou-se em $\mathrm{mg}$ $\mathrm{kg}^{-1}(*, \mathrm{p}<0,05)$ e $\mathrm{g} \mathrm{kg}^{-1}(* *, \mathrm{p}<0,01)$. Não houve efeito da adição de LE nas concentrações de $\mathrm{Al}, \mathrm{B}, \mathrm{Ca}, \mathrm{Fe}, \mathrm{K}, \mathrm{Mn}, \mathrm{Na}, \mathrm{Pb}$ e $\mathrm{Zn}$ nos colmos. Houve ainda efeito do adubo químico complementar no teor de $\mathrm{N}$ e não dos outros elementos dos colmos. Nota-se que as quantidades médias de macronutrientes $\left(\mathrm{g} \mathrm{ha}^{-1}\right)$ e de micronutrientes exportadas pelos colmos e folhas $\left(\mathrm{kg} \mathrm{ha}^{-1}\right)$ dos tratamentos testemunha e aquele que recebeu a dose de $40 \mathrm{tha}^{-1}$ de LE estão a seguir. Estes resultados são comparados com os obtidos por Orlando Filho (1978) para cultivá-la CB 41-76 colhida aos 14 meses, os quais estão dispostos entre os parênteses: $\mathrm{N}$ de 136 a $175 \mathrm{~kg}$ (167); P de 18 a $29 \mathrm{~kg}(24) ; \mathrm{K}$ de 158 a $185 \mathrm{~kg}(183) ; \mathrm{Ca}$ de 68 a $110 \mathrm{~kg}$ (96); $\mathrm{Mg}$ de 29 a $43 \mathrm{~kg}(56) ;$ de 35 a $59 \mathrm{~kg}(52) ; 319$ a $500 \mathrm{~g}$ de B (275); 140 a $247 \mathrm{~g}$ de $\mathrm{Cu}$ (245); 6000 a $7500 \mathrm{~g}$ de Fe (4940); 2860 a 3120g de Mn (2752) e de 318 a 470g de $\mathrm{Zn}$ (693). Verificou-se que as faixas de variação para as quantidades exportadas de nutrientes pelos colmos e folhas estão dentro da encontrada na literatura, excetuandose as quantidades de $\mathrm{Fe}$ e de $\mathrm{Zn}$, que foram, respectivamente, acima e abaixo destes valores. Na Figura 3, visualizam-se os efeitos de doses de LE no aumento das exportações de N, K, Ca, P, Mg, S, Al, Fe, Cu e B pela parte aérea. Destes aumentos apenas parte deles foi motivada pelos aumentos nas concentrações dos nutrientes nos colmos + folha, mas sim devido à maior produtividade. 
(a)

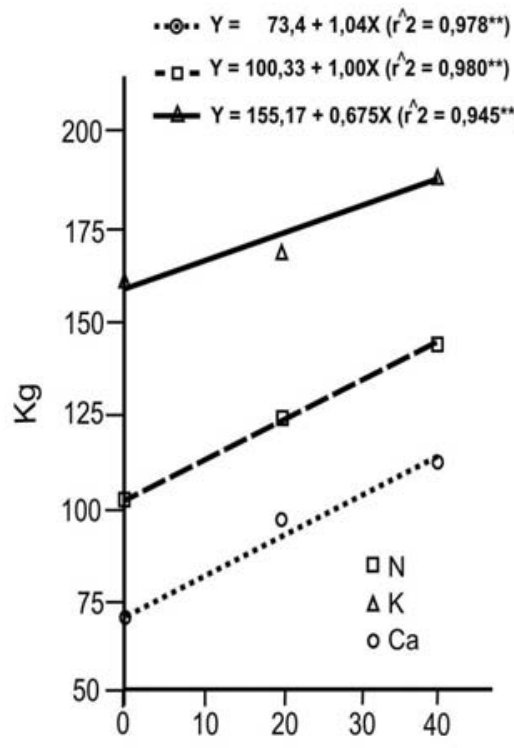

(b)

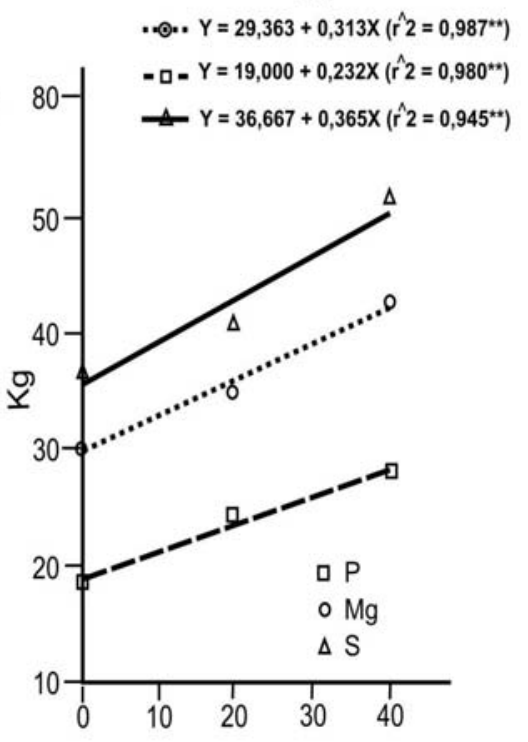

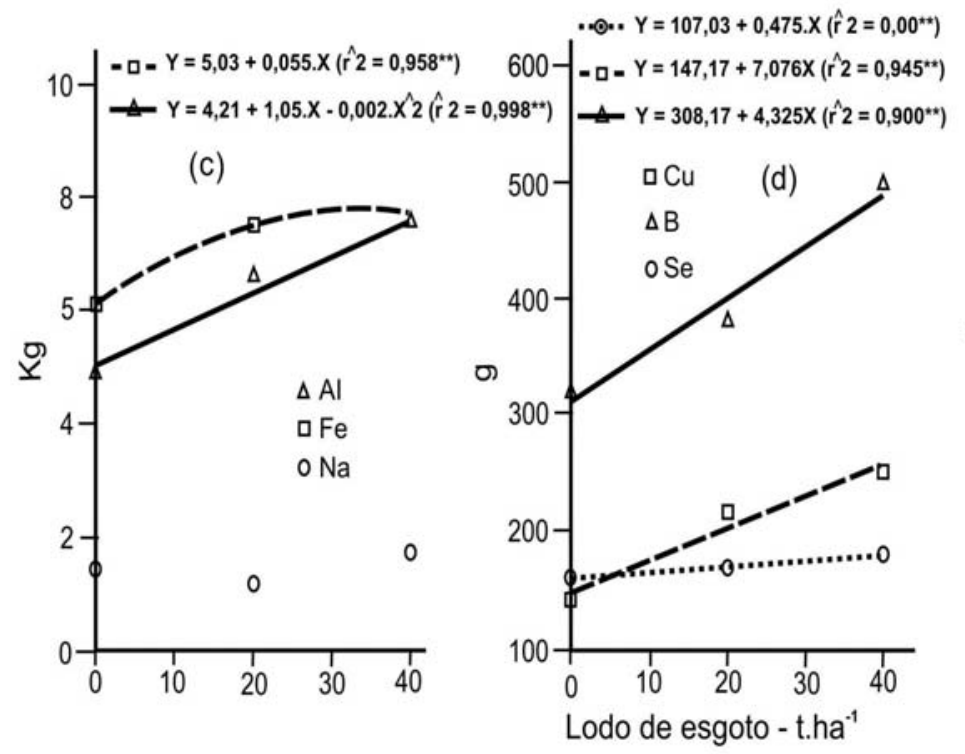

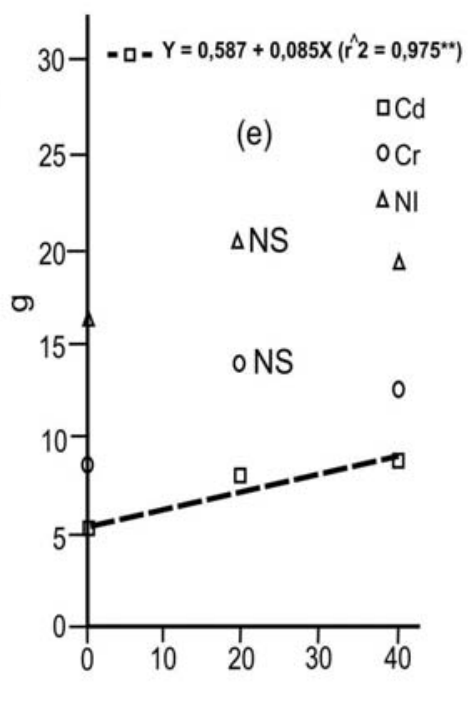

Figura 3. Influência da aplicação de doses de lodo de esgoto ao solo, na exportação de nitrogênio, de potássio, de cálcio (a), de fósforo, de magnésio, de enxofre (b), de alumínio, de ferro, de sódio (c), de cobre, de boro, de selênio (d), de cádmio, de crômio e de níquel (e) pelos colmos + folhas da cana-planta, aos 431 dap.

* e $\mathrm{e}^{* *}$ significativo a $5 \%$ e $1 \%$ de probabilidade no teste $\mathrm{F}$, respectivamente.

Os aumentos de teores dos elementos nos tecidos foliares causados pelo LE foram diferentes para cada nutriente, sendo o primeiro valor entre parênteses a testemunha, e o último para o tratamento que recebeu $40 \mathrm{t} \mathrm{ha}^{-1}$ de LE: B (4,0 para 6,0 $\left.\mathrm{g} \mathrm{t}^{-1}\right), \mathrm{Ca}\left(1,84\right.$ para 2,68 $\left.\mathrm{kg} \mathrm{t}^{-1}\right), \mathrm{Cu}\left(4,0\right.$ para $\left.5,9 \mathrm{~g} \mathrm{t}^{-1}\right), \mathrm{S}\left(1,0\right.$ para $\left.1,4 \mathrm{~kg} \mathrm{t}^{-1}\right)$ e $\mathrm{Zn}(9$ para $\left.11,3 \mathrm{~g} \mathrm{t}^{-1}\right)$, cujos valores se encontram na faixa de variação encontrada por Primavesi et al. (1992). O efeito do LE em aumentar a exportação de nutrientes pelas culturas foi observado por vários autores (Silva et al., 2000). Comparam-se, a seguir, as quantidades exportadas de nutrientes por tonelada de colmos, despontados e 
queimados, entre aos tratamentos testemunha ( $1^{\circ}$ número), e o que recebeu $40 \mathrm{t} \mathrm{ha}^{-1}$ de LE ( $2^{\circ}$ número), com a literatura para a cana-planta (cultivar CB41-76) colhida aos 16 meses (Orlando Filho, 1978), dispostos entre parênteses: $N$ de 2,2 a 2,5 $(3,0)$ $\mathrm{kg} ; 0,5$ a $0,6(0,6) \mathrm{kg}$ de P; 0,76 a 0,96 (0,90) kg de S; 10 a 11 (15) g de Zn; 44 a 37 (44) g de $\mathrm{Mn}$ e de 6,8 a 8,6 (6,25) g de $\mathrm{Cu}$. Procedendo-se a comparação dos resultados obtidos com a literatura, permitiu-se verificar que apenas o Zn nos colmos estaria mais baixo, mas perfeitamente dentro da faixa de variação encontrado por Primavesi et al. (1992).

As quantidades dos elementos, em $\mathrm{kg} \mathrm{ha}^{-1}$, aplicadas através do LE, na dose de $40 \mathrm{t} \mathrm{ha}^{-1}$, foram: B (0,15), Ca (172), Cu (14), Fe (760), K (22), Mg (52), Mn (8), N (334), P (150), S (150) e Zn (28). Comparando-se então as quantidades máximas de nutrientes exportadas pelos colmos mais folhas, com as quantidades de nutrientes adicionadas pelo LE, constata-se que o balanço foi positivo, exceto para $\mathrm{K}$ e $\mathrm{B}$, cujo balanço foi negativo. Se considerados apenas os colmos, o balanço foi positivo para todos os nutrientes, exceto para o B. A adição de LE ao solo aumentou os teores de $\mathrm{Cd}$ e $\mathrm{Ni}$ no solo e na planta, mas os aumentos foram da ordem de valor que não ofereceu qualquer risco de passagem a cadeia trófica (Figura 3).

\section{CONCLUSÕES}

1. O lodo de esgoto (LE) aplicado ao solo atuou como fertilizante e corretivo de acidez para a cultura de cana-de-açúcar, principalmente como fonte de $\mathrm{Ca}, \mathrm{P}, \mathrm{S}$ e $\mathrm{Zn}$, propiciando um melhor perfilhamento e aumento da produtividade agrícola;

2. A produtividade da cana-de-açúcar foi relacionada positivamente com a atividade da fosfatase ácida, refletindo no equilíbrio energético da cana-planta;

3. Além do teor de $\mathrm{P}$ no solo, a atividade da fosfatase foi influenciada também pela ação conjunta dos metais $\mathrm{Cu}, \mathrm{Zn}$ e B;

4. A adição de LE ao solo promoveu o incremento de produção de biomassa de colmos, o que ocasionou aumento proporcional de produtividade de açúcar e não alterou as variáveis tecnológicas;

5. O balanço dos nutrientes no sistema solo-planta foi positivo, exceto para o $\mathrm{K}$ e $\mathrm{B}$, pois as quantidades adicionadas por $40 \mathrm{t} \mathrm{ha}^{-1}$ de LE (material úmido) superaram as exportações dos nutrientes contidos na parte aérea da cana-deaçúcar.

6. A adição de LE ao solo aumentou os teores de Cd e Ni no solo e na planta, mas os aumentos foram da ordem de valor que não oferece qualquer risco de passagem a cadeia trófica. 


\section{REFERÊNCIAS}

ABREU JUNIOR, C.H.; NOGUEIRA, T.A.R.; OLIVEIRA, F.C.; PIRES, A.M.M.; FRANCO, A. Aproveitamento agrícola de resíduos no canavial. In: MARQUES, M.O.; MUTTON, M.A.; NOGUEIRA, T.A.R.; TASSO JÚNIOR, L.C.; NOGUEIRA, G.A. e BERNARDI, J.H. Tecnologias na agroindústria canavieira. Jaboticabal: FUNEP, 2008, p. 183-210.

ABREU JUNIOR, C.H.; BOARETTO, A.E.; MURAOKA, T.; KIEHL, J.C. Uso agrícola de resíduos orgânicos: propriedades químicas do solo e produção vegetal. In: VIDAL-TORRADO, P.; ALLEONI, L.R.F.; COOPER, M.; SILVA, A.P.; CARDOSO, E.J. Tópicos em Ciência do Solo, Viçosa: Sociedade Brasileira de Ciência do Solo, v. 4, p. 391-470, 2005.

BETTIOL, W; CAMARGO, O.A. Lodo de esgoto: impactos ambientais na agricultura. Embrapa Meio Ambiente, Jaguariúna, 2006. 349p.

BERTON, R.S.; CAMARGO, O.A.; VALADARES, J.M.A.S. Absorção de nutrientes pelo milho em resposta à adição de lodo de esgoto a cinco solos paulistas. Revista Brasileira de Ciência do Solo, Campinas. v.13, p.187-92, 1989.

BETTIOL, W.; CARVALHO, P.C.T.; FRANCO, B.J.D.C. Utilização do lodo de esgoto como fertilizante. O Solo, Piracicaba, v.5., n.1., 44-54p., 1983.

BETTIOL, W.; CARVALHO, P.C.T. Utilização de lodo de esgoto primário e fertilizantes organo-mineral. IPT na cultura de milho. Fertilizantes, São Paulo, v.4, n.1 p.14-5, 1982.

BRASIL. Ministério do Meio Ambiente. Conselho Nacional do Meio Ambiente. Resolução no 375, de 29 de agosto de 2006. Define critérios e procedimentos, para o uso agrícola de lodos de esgoto gerados em estações de tratamento de esgoto sanitário e seus produtos derivados, e dá outras providências. Brasília, 2006. 32p.

CAMILOTTI, F.; ANDRIOLI, I.; MARQUES, M.O.; SILVA, A.R.; TASSO JUNIOR, L.C.; NOBILE, F.O.; NOGUEIRA, G.A.; PRATI, F. Produtividade e qualidade agroindustrial da cana-de-açúcar cultivada com lodo de esgoto, vinhaça e adubos minerais. STAB: Açúcar, Álcool e Subprodutos, v. 24, p. 32-55, 2006.

CAMILOTTI, F.; MARQUES, M.O.; ANDRIOLI,I.; SILVA, A.R.; TASSO JUNIOR, L.C.; NOBILE, F.O. Acúmulo de metais pesados em cana-de-açúcar mediante a aplicação de lodo de esgoto e vinhaça. Engenharia Agrícola, Jaboticabal, v.27, n.1, p.284-293, 2007. 
CARVALHO, P.C.T. Utilização de lodos-de-esgoto na agricultura. In: COLÓQUIO REGIONAL SOBRE MATÉRIA ORGÂNICA DO SOLO, IPI/CEFER, São Paulo, 1982. p. 223-6.

CESAR, M.A.A.; DELGADO, A.A.; SILVA, F.C.da; BRESSAN, W. Avaliação da composição mineral do caldo de cana-de-açúcar, em função de variedade e época do ano. Revista Usineiro, São Paulo, v.20, 1990. 26-34p.

CETESB - COMPANHIA DE TECNOLOGIA E SANEAMENTO AMBIENTAL. Decisão de Diretoria no 195-2005-E. São Paulo, 2005.

CHIBA, M.K. Uso de lodo de esgoto na cana-de-açúcar como fonte de nitrogênio e fósforo: parâmetros de fertilidade do solo, nutrição da planta e rendimentos da cultura. 2005. 142f. Tese (Doutorado em Solos e Nutrição de Plantas) - Escola Superior de Agricultura "Luiz de Queiroz", Universidade de São Paulo, Piracicaba, 2005.

CUNNINGHAM, I.D.; KEENEY, D.R.; RYAN, J.A. Yield and metal composition of corn and rye grown on sewage sludge ammended soil. Journal Environmental Quality, Madison, v. 4, p.448-54, 1975.

DIAS, F.L.F. Efeito da aplicação de calcário, lodo de esgoto e vinhaça em solo cultivado com sorgo granífero (Sorghum bicolor $\underline{\text { L.) }}$. Jaboticabal, UNESP/FCAV, 1994. 74p.

EL WALI, A.M.O.; GASCHO, G.J. Fertilization of sugarcane using critical nutrient leves. Sugar Journal, New York, v. 46, n.80, p. 9-11, 1984.

EMBRAPA. CENTRO NACIONAL DE PESQUISA DE SOLOS. Sistema brasileiro de classificação de solos. Brasília, Embrapa Produção de Informação; Rio de Janeiro, Embrapa Solos, 1999. 412p.

ESTADOS UNIDOS. Department of agriculture. Soil taxonomy: a basic system of soil classification form making and interpreting soil surveys. Washington: USDA, 1999. 869p. (Handbook, 436)

FORTUNY, J.A.; FULLER, W.H. Trace metals in municipal sludges. Evaluation procedures for solid wastes. Biocycle. Journal of Waste Recycling, Emmaus. v. 20 n. 27, p.9, 1979.

FRANCO, A. Cana-de-açúcar cultivada em solo adubado com lodo de esgoto e vinhaça: nitrogênio no sistema solo-planta, produtividade e características 
tecnológicas. 2003. 90f. Dissertação (Mestrado em Agronomia) - Faculdade de Ciências Agrárias e Veterinárias, Universidade Estadual Paulista, Jaboticabal, 2003.

GALLOWAY, H.M.; JACOBS, L.W. Sewage sludge. I. Caracteristics and management. Utilization of municipal sewage ludges on land for agricultural production. Washington, North Central Regional Extention Publication, 1977. p.3-17.

GOLDEN, L.E. Micronutrient studies with sugarcane in Louisiana. American Society Sugarcane Technologist ${ }_{2}$ New Orleans, v. 6, n.88, p.92, 1976.

GUSHI, R.S.; BOARETTO, A.E.; NAKAGAWA, J. Utilização do lodo de esgoto em comparação com fertilizantes químicos - feijão não irrigado. In: CONGRESSO BRASILEIRO DE INICIAÇÃO CIENTÍFICA EM CIÊNCIAS AGRÁRIAS, 2, Piracicaba, 1982. Anais... Piracicaba, ESALQ. 1982, p.214-6.

HUMBERT, R.P The growing of sugarcane. New York, Elsevier, 1968. 779p.

MALAVOLTA, E. Fertilizantes e seu impacto ambiental. São Paulo, Produquímica, 1994. 191p.

MARQUES, M.O. Efeitos da aplicação de lodo de esgoto na produtividade e qualidade da cana-de-açúcar. Piracicaba, SP. 1990. 168f. Tese (Doutorado em Solos e Nutrição de Plantas) - Escola Superior de Agricultura "Luiz de Queiroz. Universidade de São Paulo-USP. 1990.

MARQUES, M.O.; BELLINGIERI, P.A.; MARQUES, T.A.; NOGUEIRA, T.A.R. Qualidade e produtividade da cana-de-açúcar cultivada em solo com doses crescentes de lodo de esgoto. Bioscience Journal, v. 23, p. 111-122, 2007 a.

MARQUES, M.O.; BELLINGIERI, W.J.; MELO, P.A.; OLIVEIRA, F.C.; FREITAS, J.C.; SANTIAGO,G. Avaliação agroindustrial de cana-de-açúcar cultivada em solo acrescido de lodo de esgoto. In: REUNIÃO BRASILEIRA DE FERTILIDADE DO SOLO E NUTRIÇÃO DE PLANTAS, 21, Petrolina, 1994. Resumo. Petrolina, Sociedade Brasileira de Ciência do Solo, 1994. p.335-6.

MARQUES, M.O.; NOGUEIRA, T.A.R.; FONSECA, I.M.; MARQUES, T.A. Teores de $\mathrm{Cr}$, $\mathrm{Ni}$, Pb e $\mathrm{Zn}$ em Argissolo Vermelho tratado com lodo de esgoto e cultivado com cana-de-açúcar. Revista de Biologia e Ciências da Terra, v. 7, p. 133-143, 2007b. 
MATTIOLLI, C. H. Métodos de Seleção de equações de regressão linear múltipla. Piracicaba, 1983. 104f. Dissertação (Mestrado em Estatística e Experimentação Agronômica) - Escola Superior de Agricultura "Luiz de Queiroz", Universidade de São Paulo. Piracicaba. 1983.

MELO, W.J. de; MARQUES, M. ${ }^{\text {; }}$ SILVA, F.C. da; BOARETTO, A.E. Uso de Resíduos Sólidos Urbanos na Agricultura e impactos Ambientais. In. Congresso Brasileiro de Ciência do solo, 20. Rio de Janeiro, 20 a 26 de Julho de 1997. Anais... CD-ROM.

MULCHI, C.L.; BELL, P.F.; ADAMU, C.; CHANEY, R.L. Long term availability of metals in sludge amended acid soils. Journal Plant Nutrition, Philadelphia, PA, 10, 1149-61p, 1987.

NOGUEIRA, T.A.R.; MARQUES, M.O.; FONSECA, I.M.; MENDONÇA, L.Q.H. Nutrientes em cana-de-açúcar de $5^{\circ}$ corte cultivada em solo tratado com lodo de esgoto e vinhaça por quatro anos consecutivos. Revista de Biologia e Ciências da Terra, Paraíba, v. 7, p. 7-19, 2007.

ORLANDO FILHO, J. Absorção dos macronutrientes pela cana-de-açúcar (Saccharum spp) variedade CB41-76, em três grandes grupos de solos no Estado de São Paulo. Piracicaba, 1978. 154f. Tese (Doutorado em Solos e Nutrição de Plantas)- Escola Superior de Agricultura “Luiz de Queiroz", Universidade de São Paulo. Piracicaba. 1978.

ORLANDO FILHO, J. Nutrição e adubação da cana de açúcar no Brasil. Rio de Janeiro, IAA/PLANALSUCAR 1983. 368p. (Coleção Planalsucar, 2).

PRIMAVESI, O.; KORNDÓRFER, G. H.; DEUBER, R. Extração de minerais por colmos de cana-planta em três solos. In: REUNIÃO BRASILEIRA DE FERTILIDADE DO SOLO E NUTRIÇÃO DE PLANTAS, 20, Piracicaba, 26 a 31 de Julho, 1992.

Anais... SBCS / ESALQ e CENA/USP, Fundação Cargill, Piracicaba, 1992. 0.160-1.

RAIJ, B. van; CANTARELLA, H.; QUAGGIO, J.A.; FURLANI, A.M.C. Recomendações de adubação e calagem no Estado de São Paulo. 2.ed. Campinas Instituto Agronômico, 1996. 300p.

ROS, C.O. da; AITA, C.; CERETTAM C.A.; FRIES, M.R. Lodo de esgoto: efeito imediato no milheto e residual na associação aveia-ervilhaca. Revista Brasileira de Ciência do Solo, Campinas, v.17, n.2, p.257-61, 1993. 
SILVA, F.C. da. Manual de análises químicas de solos, plantas e fertilizantes. 2. ed. Embrapa, Brasília, 2009. 627p.

SILVA, F.C.; FANTE JUNIOR, L.; PILOTTO, J.E.; RODRIGUES, J.A.; BOARETTO, A.E.; OLIVEIRA, J.C.M.; BERTON, R.S.; ZOTELLI, H.B.

Evaluating the residual effects of sludge in root distribution an heavy metals in sugar cane crop. International Sugar Journal, London, v. 102, p. 424-30, 2000.

SILVA, F.C. da; FANTE Jr., L.; RODRIGUES, J.A; PILOTTO, J.E.; BOARETTO, A.E.; OLIVEIRA, J.C.M. de; BERTON, R.S.; ZOTELLI, H.B. Efeitos do lodo de esgoto na distribuição radicular e nos teores de metais pesados em cana-de-açúcar.

Revista Biociências, Taubaté, v.2, n.2, p.125-139, jul/dez, 1996.

SILVA, F.C. da. Uso Agronômico de Lodo de Esgoto: Efeitos em Fertilidade do Solo e Qualidade da Cana-de-Açúcar. 1995. 159f. Tese (Doutorado em Solos e Nutrição de Plantas) - Escola Superior de Agricultura "Luiz de Queiroz", Universidade de São Paulo. Piracicaba. 1995.

SILVA, F.C. da ; BASSO, L.C. Avaliação da atividade in vivo da fosfatase ácida da folha na diagnose da nutrição fosfórica em cana-de-açúcar. Revista Agropecuária Brasileira, Campinas, v.17, p.371-375, 1993.

SOMMERS, L.E. Chemical composition of sewage sludge and analysis of their potential use as fertilizer. Journal Environmental Quality, Madison, 6:225-31, 1977.

TASSO JÚNIOR, L.C.; MARQUES, M.O.; FRANCO, A.; NOGUEIRA, G.A.; NOBILE, F.O.; CAMILOTTI, F.; SILVA A.R. Produtividade e qualidade de canade-açúcar cultivada em solo tratado com lodo de esgoto, vinhaça e adubos minerais. Engenharia Agrícola, v. 27, p. 276-283, 2007.

TSUTIYA, M.T. Alternativas de disposição final de lodo de esgotos. In: TSUTIYA, M.T. et al. Lodo de esgotos na agricultura. 2. ed. São Paulo: ABES/SP, 2002. p.133-180. 